\title{
ACTIONS OF VERATRAMINE ON THE CENTRAL NERVOUS SYSTEM
}

\author{
KEIZO FUKUMA* \\ Department of Pharmacology, Tottori Unizersity School of Madicine, Yonago \\ Received for publication November 25, 195.5
}

Veratramine, a secondary amine of veratrum alkaloids, was isolated first by Saito (1) from the Japanesc Veratrum grandiflorum and found later by Jacobs and Craig (2) in the American Veratrum viride. Its pharmacological actions were studied first by Krayer (3) and later by many investigators. The most important property of this alkaloid is considered to be the antiaccelerator action on the heart, which was discovered by Krayer and has been thoroughly studied by him and his coworkers $(4 \sim 10)$.

Another remarkable action of veratramine is the excitatory action on the contral nervous system. This was found also by Krayer at the same time the antiaccelerator was discovered, but relatively little attention has been focused on this subjert ever since. Krayer, the first reporter, described briefly that clonic convulsion occurred in dogs and it was suppressed by pentobarbital. Few other investigators observed also convulsive action of veratramine while they studied on its cardiovascular action (11 13). However nobody had studied in detail on its central action until Tanaka (14) took up this project. In his study on the central actions of veratrum alkaloids in mice, Tanaka pointed out that veratramine caused a unique excitation which was expressed as "struggling" movement and was antagonized by mephenesin or ether. Despite his relatively comprehensive survey on this project, the site of action of veratramine remained unelucidated.

The present investigation was designed to supplement the study of Tanaka on the central action of veratramine, by determining if the same excitation could be observed in other species of experimental animal, by scarching for the antagonists against the excitation, by observing the influence of climination of some parts of brain, by recording the electroencephalogram and by studying the circulatory effect when administared directly to the rentral nervous system.

\section{METHODS}

Rabbits weighing 2-3.5 kg were used as major experimental animals. Cats, guinca pigs and puppies were also employed for comparison. In order to avoid the possible change of susceptibility to the drug, the same animal was not utilized before 48 hours clapsed. Besides, the intracisternal injection was not repeated more than five times in

\footnotetext{
* Director: Prof. Kiyoshi Tanaka
} 
the same animal.

Operations of brain were performed in unancsthetized or temporarily etherized cats. The skull was exposed and perforatef by means of hand drill and rongeurs ayoiding to injure the transverse venous sinus, ant bleeding was controlled by tcmporary cramping of bilateral carotid arteries. The dura was removed and the motor arca or the dorsal and lateral surfaces of cortex were excised by a spatula in the depth of $8 \mathrm{~mm}$. Bilalateral hemispherectomy, prc- inter- and post-collicular transections were performed utilizing the same spatula.

Electroencephalogram was recorded by 2 channel inkwriter in the speed of $3 \mathrm{~cm}$ per second. Unipolar electrodes were applied on dura of one side of frontal as well as parietal lobe. The indifferent electrode was placed on the skin surface of an ear.

Arterial pressure was recorded by means of mercury manometer connected to a carotid artery and respiration was registered through Marey-tambour connected to a tracheal cannula, both on a smoked drum.

Ten milligram of veratramine* was ground with an obsidian mortar and brought to $0.1 \%$ solution by adding 0.4 c.c. of $\mathrm{N} / 10$ hydrochloric acid and 9.6 c.c. of distilled water. This solution was injected intravenously in all species of animal and intracisternally in rabbits. All doses refer to the base.

Drugs employed in the experiment of antagonists were: cther, urethane, phenobarbital sodium, diphenylhydantoin sodium, trimethadione (Tridione), morphine hydrochloride, mephenesin (Myanesin), aminopyrine, procaine hydrochloride, diphenhydramine (Benadryl), chlorpromazine and benzylimidazoline (Priscol).

\section{RESULTS}

\section{Excitatory effects of veratramine on sevaral species of experimental animal}

\section{Rabbits}

(a) Intravenous injection. When veratramine in the dose of $0.2 \mathrm{mg} / \mathrm{kg}$ ivas injected into the ear vein as quickly as possible, restlessness, scared appearance, slight ataxia and difficulty to maintain equilibrium were observable for 7-8 minutes. A rapid injection of $0.4-0.5 \mathrm{mg} / \mathrm{kg}$ gave usually risc to a typical motor excitement. With the latency of 30 seconds the first signs of excitement emerged in the aspects of restlessness, swaying the body back and forth, ataxia, pilomotor and miosis. Subscquently the animal spread the four limbs and displayed tremor which was observable in the whole body but was particularly distinct in the four extremities. Struggling movement followed immcdiately, i.e. 1 or $1 \frac{1}{2}$ minutes after the injection. This was characterized by a violent irregular movement of four limbs, resembling swimming but aimless and involuntary. Tachypnea, salivation, gritting of teeth and lateral nystagmus were accompanied at the same time. In the more severe cases, rotation around the longitudinal axis and sometimes running

* Veratramine was supplied through the courtesy of Dr. Otto Krayer, Harvard Medical School, Boston, U.S.A. 
movement in the recumbant position were manifested. The struggling movement reached maximum in 1-2 minutes after the injection and lasted for 4-5 minutes, then the movement became intermittent, subsided totally in 15-20 minutes and followed by an exhausted state which lasted for 5-10 minutes.

The doses required for tremor and struggling are shown in Table 1, and the aspects of excitation are illustrated in Figure 1.

TABLE 1. The relationship between intravenous dosage and responses

\begin{tabular}{l|c|c}
\hline \multirow{2}{*}{ Dose $(\mathrm{mg} / \mathrm{kg})$} & \multicolumn{2}{|c|}{ Reacted/tested number of animals } \\
\cline { 2 - 3 } & Tremor & Struggling \\
\hline 0.2 & $0 / 5(0 \% \%)$ & $0 / 5(0 \%)$ \\
0.25 & $1 / 8(13 \%)$ & $0 / 8(0 \%)$ \\
0.3 & $1 / 5(20 \% \%)$ & $0 / 5(0 \%)$ \\
0.35 & $3 / 8(38 \%)$ & $1 / 8(13 \%)$ \\
0.4 & $3 / 5(60 \%)$ & $3 / 5(60 \%)$ \\
0.45 & $5 / 5(100 \%)$ & $4 / 5(80 \%)$ \\
0.5 & $8 / 8(100 \%)$ & $7 / 8(87 \%)$ \\
\hline $\mathrm{ED}_{\overline{5} \mathrm{o}}$ & $0.37(0.324-$ & $0.41(0.369-$ \\
\hline
\end{tabular}

* $95 \%$ confidence limits
TABLE 2. The relationship between intracisternal dosage and responses

\begin{tabular}{c|cc}
\hline \multirow{2}{*}{ Dose $(\mathrm{mg} / \mathrm{kg})$} & \multicolumn{2}{|c}{ Reacted/tested } \\
& Tremor & Struggling \\
\hline 0.01 & $0 / 5(0 \%)$ & $0 / 5(0 \%)$ \\
0.015 & $1 / 5(20 \%)$ & $0 / 5(0 \%)$ \\
0.02 & $3 / 5(60 \%)$ & $1 / 5(20 \%)$ \\
0.03 & $5 / 5(100 \%)$ & $3 / 5(60 \%)$ \\
0.04 & $5 / 5(100 \%)$ & $4 / 5(80 \%)$ \\
0.045 & $5 / 5(100 \%)$ & $5 / 5(100 \%)$ \\
\hline $\mathrm{ED}_{50}$ & $0.019(0.0158-$ & $0.029(0.0214$ \\
\hline
\end{tabular}

* 95\% confidence limits

(b) Intracisternal injection. The symptoms of excitation caused by the intracisternal injection of veratramine were qualitatively same as those by the intravenous injection but differed quantitatively in many respects. The latency was longer (one minute after the injection), the phase of tremor was more marked (lasted for one minute), the struggling movement reached maximum slowly (4--7 minutes after the injection) and persisted longer (the continuous struggling for 15 minutes and the intermittent one for 10 minutes).

During the struggling the animal shook vigorously the downward bent head horizontally. The tremor subsisted for a while even when struggling subsided completely. In the severc cases, the animal lost the righting reflex and exhibited rotation sometimes accompanied by jumping fits but rarely by running movement. The largest dose tried was $0.05 \mathrm{mg} / \mathrm{kg}$ and it was still not lethal. Cessation of the excitement was always followed by a state of exhaustion.

After all, the excitation caused by the intracisternal veratramine was more prominent than that by intravenous injection. Intracisternal effective doses, as shown in Table 2 , were calculated as $1 / 15-1 / 20$ of intravenous doses.

The possibility of tachyphylaxis was explored by a repeated injection of veratramine. The second intracisternal veratramine in the dose of $0.045 \mathrm{mg} / \mathrm{kg}$ was applied to the rabbits which had received the same dose 60 minutes prior to the second injection. This animal manifested a typical excitement of which grade was the same or rather severe as before. This suggests no tendency of tachyphylaxis but of cumulation. 


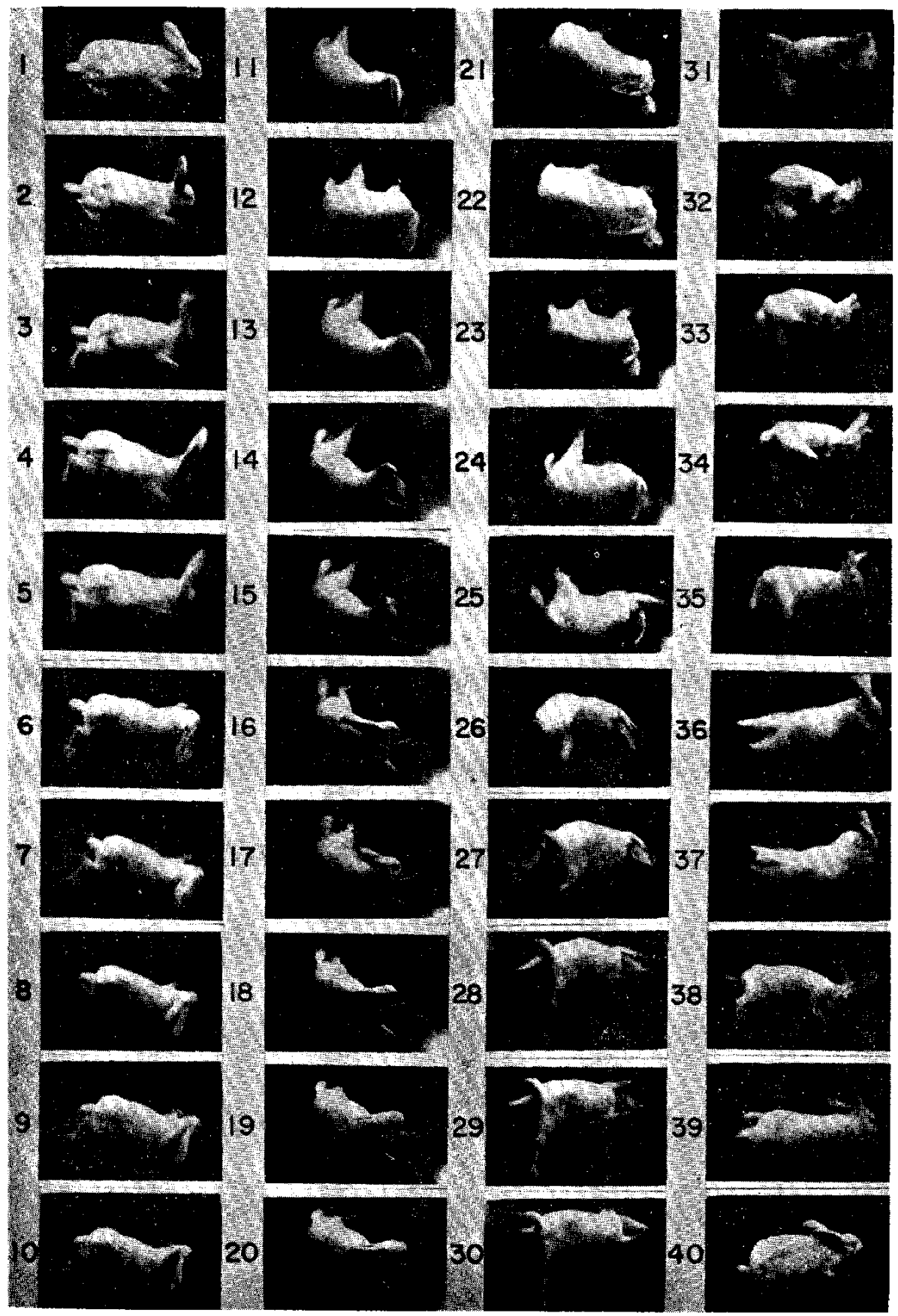

FIG. 1. Excitation induced by veratramine (cinematographic observation). (1) direct after the intravenous injection of veratramine in the dose of $0.5 \mathrm{mg} / \mathrm{kg}$, (2) 30 seconds after the injection, beginning of tremor, (3-5) 1 minute, beginning of struggling, (6-10) 1.5 minutes, (11-20) 2 minutes, (2125) 2.5 minutes, (26-30) 3 minutes, (31-37) 3.5 minutes after the injection, demonstrating struggling and rotating movement, (38) postexcitatory depression, (39) recovering period, (40) completely recovered. 


\section{Guinea pigs}

Intravenous veratramine in the dose of $0.4-0.5 \mathrm{mg} / \mathrm{kg}$ caused the analogous excitation to that of rabbits. With the latency of 30 seconds the first symptoms appeared which was swaying the body back and forth and head up and down. This was followcd by tremor and subsequently by struggling movement, which persisted for 6-8 minutes. Rotation and running movement in the recumbant position were also observablc in the severe cases.

\section{Cats}

Intravenous veratramine in the dose of $0.2-0.3 \mathrm{mg} / \mathrm{kg}$ usually induced tremor and $0.4-0.5 \mathrm{mg} / \mathrm{kg}$ struggling movement. The prodromal symptoms were consisted of nystagmus, restlcssness and mydriasis. When tremor was manifested, the animal spread the four limbs so that it protected itself from falling down due to the lack of stability. Struggling appeared in a half or one minute after the injection and progressed similarly to the casc of intracisternal injcction in rabbits. Contrary to the rabbit which bent the head downward, the cat usually held the head in mild opisthotonus. In the severe case, it lied rccumbant and displayed short durating tonic and clonic convulsion interposed in the course of struggling movement. Extreme salivation, urination, lolling of the tongue and crying at times were often observed. After struggling ceased in 15 minutes tremor still remained and it required nearly 50 minutes for all the motor excitement to subside. A state of exhaustion followed after that.

\section{4. $\operatorname{Dog} 3$}

Puppies weighing $2.5-3.0 \mathrm{~kg}$ were employed and they reacted fairly sensitively. Intravenous veratramine in the dose of $0.1-0.2 \mathrm{mg} / \mathrm{kg}$ resulted in restlessness, marked ataxia and tremor of which characteristic was commencing from the hind limbs. Following the injcction in the dose of $0.25 \mathrm{mg} / \mathrm{kg}$ struggling movement was displayed. The animal took a recumbant position and rotated at times, but tonic convulsion was not combined.

In conclusion, the four species of animal tested, namely rabbits, guinea pigs, cats and dogs, reacted to veratramine fundamentally the same, although slight differcnces in the appearance of motor excitement were recognizable. In addition, their aspects coincide with those obscrved in mice by Tanaka.

\section{Influences of various drugs on the excitation induced by intracisternal veratramine in rubbits}

Veratramine in the dose of $0.04 \mathrm{mg} / \mathrm{kg}$ which corresponds to the theoretical ED for tremor and to the $E D_{33}$ for struggling was applied intracisternally in rabbits. Each group of animals receiving a single dose consisted of 5 rabbits. Before or after the veratramine administration various drugs were injected intravenously and the number of animals in which the central effect was modified by the medication was recorded. The results are summarized in Table 3. In this table, the first of the two doses listed 
TABLE 3. Iniluence of various drugs on the excitation induced by veratramine

\begin{tabular}{|c|c|c|c|c|c|c|c|c|}
\hline \multirow{2}{*}{ Drug } & \multirow{2}{*}{$\begin{array}{c}\text { Dose } \\
(\mathrm{mg} / \mathrm{kg})\end{array}$} & \multirow{2}{*}{$\begin{array}{c}\text { Interval } \\
\text { of Admin. } \\
(\mathrm{min})\end{array}$} & \multirow{2}{*}{$\begin{array}{c}\text { Total } \\
\text { No. of } \\
\text { Rabbits }\end{array}$} & \multicolumn{4}{|c|}{$\begin{array}{c}\text { Symptom of Excitation } \\
\text { (No. of Animals) }\end{array}$} & \multirow{2}{*}{$\begin{array}{l}\text { Antiex- } \\
\text { citatory } \\
\text { Activity }\end{array}$} \\
\hline & & & & $\begin{array}{l}\text { Restless- } \\
\text { ness. }\end{array}$ & $\begin{array}{l}\text { Nystag- } \\
\text { mus }\end{array}$ & Tremor & $\begin{array}{l}\text { Strug- } \\
\text { gling }\end{array}$ & \\
\hline Phenobarbital sodium & 20 & 15 & 5 & 3 & 3 & 4 & 0 & + \\
\hline " & 10 & 5 & 5 & 5 & 4 & 5 & 5 & - \\
\hline Diphenylhydantoin sodium & 20 & 2 & 5 & 4 & 2 & 1 & 0 & + \\
\hline$" \prime$ & 10 & 2 & 5 & 5 & 5 & 4 & 4 & - \\
\hline Trimethadione & 200 & 2 & 5 & 5 & 5 & 5 & 0 & $t$ \\
\hline Ether & 200 & $-3^{*}$ & 5 & 0 & 2 & 0 & 0 & H \\
\hline$"$ & 100 & $-3^{*}$ & 5 & 0 & 3 & 0 & 0 & $H$ \\
\hline Urethane & 100 & 5 & 5 & 5 & 5 & 5 & 5 & - \\
\hline$"$ & 400 & 5 & 5 & 5 & 0 & 0 & 0 & H \\
\hline Morphine & 2 & 5 & 5 & 5 & 4 & 5 & 4 & - \\
\hline ") & 5 & 5 & 5 & 1 & 0 & 2 & 1 & $-1-$ \\
\hline$\Delta$ minopyrine & 20 & 15 & 5 & 3 & 1 & 0 & 0 & H \\
\hline " & 10 & 15 & 5 & 5 & 5 & 5 & 4 & - \\
\hline Mephenesin & 30 & $-3 *$ & 5 & 0 & 4 & 0 & 0 & + \\
\hline i) & 10 & $-3 *$ & 5 & 2 & 4 & 0 & 2 & 1 \\
\hline Diphenhydramine & 5 & 10 & 5 & 5 & 4 & 4 & 4 & - \\
\hline Procaine & 10 & $-3 *$ & 5 & 3 & 5 & 5 & 5 & - \\
\hline Chlorpromazine & 2 & 3 & 5 & 3 & 5 & 5 & 5 & $-\ldots$ \\
\hline$"$ & 5 & 5 & 5 & 2 & 5 & 5 & 4 & - \\
\hline
\end{tabular}

Veratramine in the dose of $0.04 \mathrm{mg} / \mathrm{kg}$ was injected intracisternally in each case.

* The symbol $(-)$ denotes that the drug was given after veratramine.

for the antagonizing drugs is the maximal dose which does not change the behavior of normal rabbit, the second dose, 2-4 times or $1 / 2-1 / 3$, was selected according to the effectiveness of the first.

Antiexcitatory activities of the tested drugs were judged by the number of animals in which the struggling or tremor was suppressed. The sign $(H)$ indicates the complete abolishment of both struggling and tremor; (+) represents the abolishment of one of them or the marked suppression of both of them; and (-) means inability to modify the excitation significantly.

Three anticonvulsant agents, phenobarbital, diphenylhydantoin and trimethadione inhibited the struggling but not tremor by the pretreatment with a nontoxic dose. Ether in $10 \%$ saline solution and mephenesin in $5 \%$ propylene glycol solution suppressed both struggling and tremor completely as soon as they were injected intravenously; but their inhibitory effect lasted only for 3-5 minutes and the second or even the third injection was necessary to maintain the complete suppression.

Urethane in a slight anesthetic dose could not influence the veratramine excitation, though its deep anesthetic dose was effective. Morphine in a large dose was also capable to modify the cxcitation, and aminopyrine also counteracted veratramine struggling. 
Procaine and diphenhydramine had no appreciable effect and chlorpromazine could not suppress either struggling or tremor even in the paralyzing dose.

\section{Infuences of transections of brain on the excitation induced by intravenous veratramine in cats}

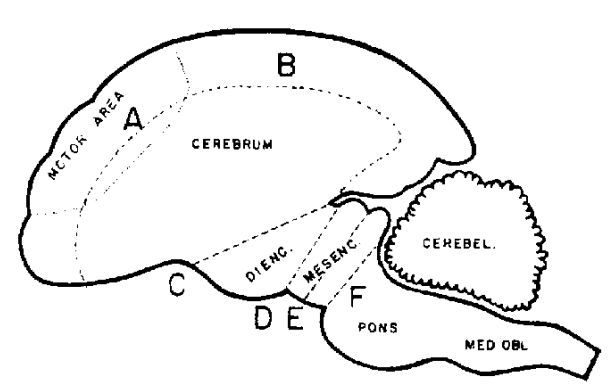

FIG. 2. Schema of brain indicating the levels of section
A. Bilateral ablation of motor area of cercbral cortex
B. Bilateral decortication
C. Bilateral ablation of cerebral hemisphere
D. Transection between diencephalon and midbrain
E. Intercollicular transection
F. Transection between midbrain and pons

Excisions or transections in several levels of cat's brain were tried in order to cxplore the site of action of veratramine. The levels of section were shown in Figure 2. After the cat recovered from the shock of operation, veratramine in the dose of 0.5 $\mathrm{mg} / \mathrm{kg}$, which caused violent struggling in normal cats, was applied intravenously.

\section{Bilateral ablation of motor area of certbral corlex}

Bilateral gyri sigmoidei anterior and posterior including their vicinity were excised. One hour later veratramine was administered and the excitation was observed in detail. With the latency of 30 seconds the prodromal symptoms such as spreading the fore limbs or opisthotonus of the head were manifested. These were followed by the struggling movement which was weaker than that of normal animal. It was characterized by interposing of pauses; in other words the struggling appeared intermittently even at its maximal stage. Tremor was also intermittent and less marked than the case of normal cats. Sometimes the cat crossed the both fore limbs in front of its breast lying in the lateral position. The whole excitation lasted for $10-15$ minutes.

\section{Bilateral decorication}

One hour after the operation veratramine was administered. The similar prodromes to the preceding expcriment were observed and followed by struggling. There were intermissions in struggling movements, and the fore limbs predominated the hind limbs in the intensity of the movement. Crossing the fore limbs or monentary extension of the hind limbs were at times observed. Comparing with the case of the ablation of motor area, the severity of struggling was less and the tempo of the movement was slower in the decorticatc animals. When the excitation began to subside, the interval between struggling movements prolonged, and all symptoms disappeared within 15 minutes.

\section{Bilateral ablation of cerbal himisphere ivolving striate budy}

'Iwo hours after the operation veratramine was injecter. The first sign of excitement, twitching of paws, appeared with the latency of 30 scconds. This was soon followed by tremor and subsequently by struggling. The type of struggling in this case differcd 
from the normal as well as two aforesaid cases in that it was more regular and rather rhythmical resembling running movement. In addition, the intensity of the movement was more potent, the tempo was quicker and the intermissions wcre shorter than the case of decorticate animal. The movement appeared more prominently in the fore limbs than in the hind limbs. The animal displayed at times crossing of the fore limbs, extension of the hind limbs, gritting of the teeth or swinging of the tail. All excitements subsided within 20 minutes.

\section{Transection bztwoen diencephalon and micibain}

Thirty minutes after the operation veratramine was injected. With the latency of 30 seconds, tremor of paws, swinging of tail commenced and followed by struggling or, rather to say, by running movement. The movement was manifested equally in fore limbs as well as in hind limbs, but its intensity was weaker and the duration was shorter than the case of the preceding experiment. During the running movement, momentary tonic extensor convulsion and dorsal or ventral ficxion of the head were also observed. When 10-15 minutes elapsed the running subsided and only twitching of paws were left which also disappeared in 20 minutes.

\section{Intercollicular transecion}

Veratramine injected thirty minutes after the operation caused running movement of hind limbs with tonic extension of fore limbs. This movement was accompanicd by swinging of tail but no more by tremor. Dorsal flexion of the head was at times observed. The running movement was slightly less potent than that of the preceding case and its duration was $7-8$ minutes.

\section{Transecion batween midbrain and pons}

Thirty minutes after the operation veratramine was administered. Neither tremor, struggling nor running was manifestcd. 'The effect of the drug was visible only in the slightest flexion of paws, though it was almost negligible.

\section{Influence of veratramine on the eleciroencephalogram in rabbits}

Veratramine injected intravenously in the dose of $0.2 \mathrm{mg} / \mathrm{kg}$, which did not induce tremor or struggling, increased the frequency as well as the amplitude of the brain activity. The activation was distinctly manifested two minutes after the injcction and it turned to an extinction after five minutes (Fig. 3).

When the dose of $0.4 \mathrm{mg} / \mathrm{kg}$ was administered and tremor was induced, the fast activities increased the voltage remarkably. Once struggling movement commenced spikes were interposed on the continuous fast waves.

Veratramine injected intracisternally in the dose of $0.02-0.04 \mathrm{mg} / \mathrm{kg}$ induced the similar changes in EEG to the case of intravenous injection, though the activation was manifested only when some motor excitement was elicited. During the struggling the pattern of EEG consisted of fast activities and spikes, and the slow waves disappeared entirely. 


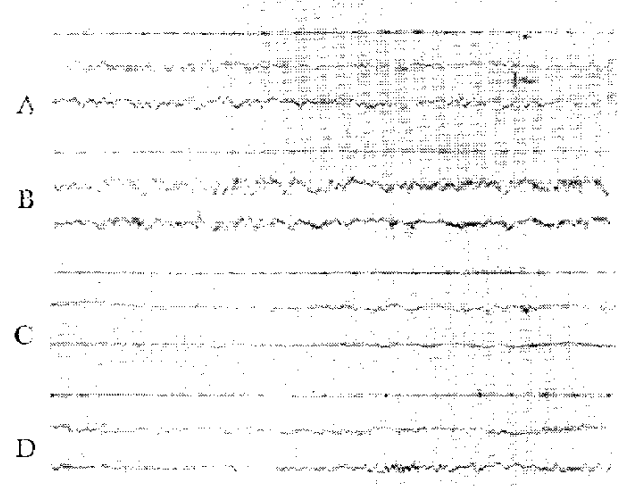

FIG, 3. EEG in the normal rabbit

A. Record taken before administration of veratramine

B. 2 minutes after intravenous injection of veratramine $0.2 \mathrm{mg} / \mathrm{kg}$

C. 5 minutes after injection

D. 25 minutes after injection

The upper tracing of each record was lead from frontal and the lower from parietal lobe.

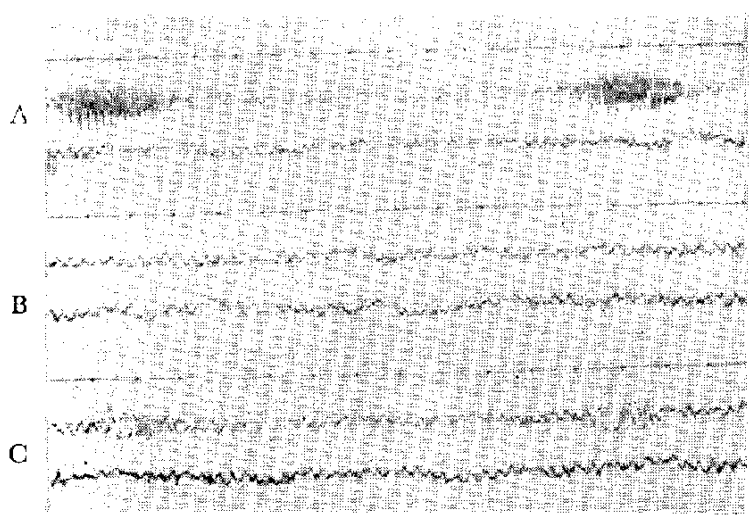

Fic. 4. EEG in the mesencephalic preparation

A. Record taken before administration of veratramine

B. 3 minutes after intravenous injection of veratramine $0.4 \mathrm{mg} / \mathrm{kg}$

C. 20 minutes afier injection

The upper tracing of each record was lead from frontal, and the lower from parietal lobe of cortex.

The combination of mephenesin in the dose of $10 \mathrm{mg} / \mathrm{kg}$ with the intracisternal veratramine in the dose of $0.04 \mathrm{mg} / \mathrm{kg}$ prevented struggling as well as the change of EEG pattern.

In the mesencephalic preparation (cricau issié of Bremer), veratramine was applied iatravenously. No struggling was observed in this case. Marked spindle bursts of 12 $14 \mathrm{c} / \mathrm{sec}$ appearing intermittently with the interval of $10-15$ seconds during the control period, disappeared entirely after the veratramine administration and reappeared 20 minutes later. The spindle bursts were replaced by fast activities of low voltage interposed on the slow activities of $4-5 \mathrm{c} / \mathrm{sec}$, but spikes were not produced (Fig. 4).

\section{Cirulatory-resfirutory effects of intracisterall verutrumine in rubbits}

Veratramine injected intracisternally in the dose of $0.02 \mathrm{mg} / \mathrm{kg}$ caused usually a transient hypotension followed by persistent hypertension which reached $+20 \sim 30 \mathrm{mmHg}$ and lasted for 15 minutes. Respiratory inhibition appeared immediately after the injection and lasted longer than the hypertension.

When $0.04-0.05 \mathrm{mg} / \mathrm{kg}$ was injected, the transient hypotension registered $-0 \sim 40$ $\mathrm{mmHg}$ and the subsequent hypertension $+10 \sim 50 \mathrm{mmHg}$ (Fig. 5A). The cardiac rate in the hypertensive phase indicated a slight diminution (approximately 20\%). Respiratory inhibition was not so serious but persisted for a long time.

The second intracisternal injection of the same dose one hour after the first, namely when the hypertension was restorcd completely to the normal level but the respiratory inhibition still remained, produced the equal or rather stronger hypertension accompanied 

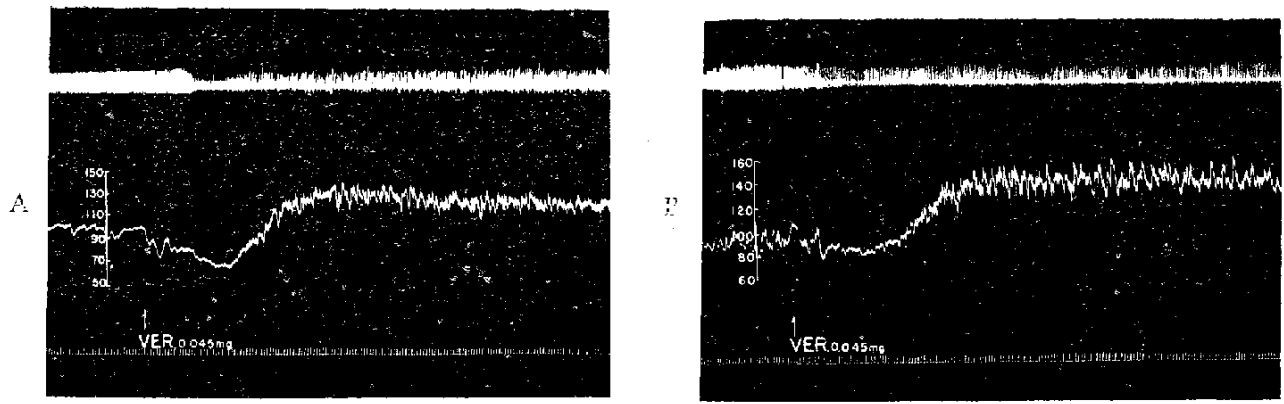

Fic. 5. Girculatory-resp:ratoy cficcts of intracisternal veratramice in the normal rabbit.

A. The first injection of veralramine $0.045 \mathrm{mg} / \mathrm{kg}$

B. The second injection of the same dose one hour after the first

Upper tracing : respiratio 2 , lower tracing : carotid arterial pressure, time: 6 sec.

by the respiratory inhibition of the same degrce as the case of the first injection (Fig. $5 B)$. In other words, no tendency of tachyphylaxis was recognized.

In order to ascertain the possible site of action of veratramine on the spinal cord, intrathecal application at the level of L2 was attempted. The holes were made in the vertebrae of L2-3 as well as $\mathrm{C} 2-3$ and two pieces of polyethylene tube were inserted into these holes so that the injected liquid from the lumbar part could not reach the oblongate medulla. Veratramine injected from the lumbar hole in the dose of 0.04 $\mathrm{mg} / \mathrm{kg}$ caused no change in blosd pressure.

Another experiment was performed in the decarebrate rabbit. $\Lambda$ fter transected between midbrain and pons, the animal received $0.045 \mathrm{mg} / \mathrm{kg}$ of veratramine intracisternally under the artificial respiration. The arterial pressure rose approximately 30 $\mathrm{mmHg}$ as is the case of normal animal (Fig. 6).

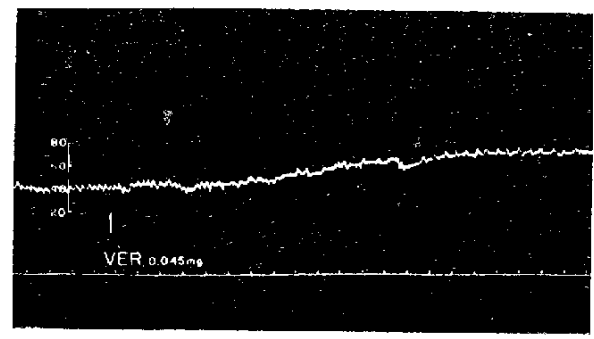

FIG. 6. Circulatory effect of intracisternal veratramine in the pons-animal Time. 18 sec.

\section{DISCUSSION}

\section{Th? mechanism of veratramine siruggling}

The unique type of excitation following veratramine administration in mice was expressed with the term of "struggling" movement by Tanaka. In the present study this is proved to be the common symptom among many species of experimental animal.

The mechanism of the veratramine exciternsnt was explored in the experiment of brain transection in cats. The fact that the struggling movement diminished its severity as well as irrcgularity following the removal of the motor areas or of the total cortex, indicates that cerebral cortex is indispensable to manifest a perfect struggling but unneccssary to initiatc the excitement. When bilateral hemisphere was ablated involving striate body, the struggling was shifted to a rather regular movement i.c. running movement. 
This suggests the important role of cerebral nuclei. Since the running movement was finally abolished following the transection between midbrain and pons, it is obvious that midbrain is responsible to initiate the veratramine excitement. Thus, the whole part rostral than midbrain contributes to acromplish the veratramine struggling.

The balance between the facilatory impulse from the cerebral cortex to the midbrain reticular formation and the inhibitory impulse from the striate body to the cortex was regarded by Hayashi (15) necessary to keep the normal locomotion. The struggling and tremor should be initiated by its unbalance due to the stimulating effect of veratramine on the midbrain reticular formation and be complicated by the stimulation of cerebral nuclei and cortex.

\section{The site of aciion of veratramine in the central nervous system}

As stated above, veratramine causes motor excitement by stimulating the brain rostral than midbrain. Although mesencephalic reticular formation is conceivable to be the foremost site of action, other parts of brain such as diencephalon, cerebral nuclei and cortex should participate in the manifestation of veratramine struggling.

Antagonists against veratramine excitement appear to display their inhibitory effect on one of these sites of action. For instance, mephenesin which is a potent antagonist against veratramine is known as the depressant of midbrain reticular formation (16, 17) and aminopyrine, another antagonist, is believed to act chiefly on dicncephalon and its vicinity. Ether which counteracts veratramine seems to have its main action on the cerebral cortex. Some of these antagonists may inhibit the initiation of struggling and others depress the spreading of the impulse which otherwise should accomplish the struggling.

Comparison of the inhibitory effects of various drugs on the nicotine tremor (18) as well as on the tonic extensor phase of maximal electroshock seizure (19) with the present data on the veratramine struggling is listed in Table 4. These experiments were all

TABLE 4. Comparison of antagonists against tonic extensor convulsion of maximal electroshock seizure (M.E.S.), nicotine-induced tremor and veratramine struggling

\begin{tabular}{l|c|c|c}
\hline \multicolumn{1}{c|}{ Antagonist } & $\begin{array}{c}\text { M.E.S. Tonic } \\
\text { Fxtensor }\end{array}$ & Nicotine Tremor & $\begin{array}{c}\text { Veratramine } \\
\text { Struggling }\end{array}$ \\
\hline Phenobarbital & + & + & + \\
Diphenylhydantoin & + & + & +1 \\
Trimethadione & \pm & + & + \\
Ether & \pm & -1 & $+t$ \\
Urethanc & \pm & - & \pm \\
Morphine & -- & + & + \\
Aminopyrine & - & + & + \\
Mephenesin & + & + & - \\
Procaine & + & + & - \\
Diphenhydramine & + & + & + \\
\hline
\end{tabular}

The symbol $\left(\frac{1}{1}\right)$ denotes the strongest, ( 1 ) moderate, ( 1 ) indistinct antagonistic activity and (-) indicates the lack of counteraction, 
performed in our laboratory in the same species of animal, i.e. rabbits. It is interesting to know from this table that many drugs influence in different way on the three types of excitation, whereas some agents such as urethane behave equally in the three cases. The locus of brain responsible to the tonic extensor seizure is regarded by Tanaka \& Mishima (20) as lower pons or medulla oblongata, and that to the nicotine tremor is considered by Kimura (18) to be midbrain. The difference in the activity to antagonize these excitation may suggest the different sites of action of these drugs.

Veratramine administered intracisternally produced a rise of arterial pressure, contrary to the hypotension in the case of intravenous injection. This is also true in the case of unpurified veratrum alkaloids mixture $(21,22)$ or of veratridine, cevadine and protoveratrine (23). Therefore, the specific action of veratramine on the vasomotor center appears to be doubtful. To the pressor action of intracisternal veratramine the oblongate medulla should be responsible, since the transection between midbrain and pons did not modify that action and the application to the lumbar intrathecal space was ineffective. The discrepancy of this result from that of Wang et al. (24), who observed an inhibitory effect of veratramine on the vasomotor center in cats, may be attributed to the difference of the route of administration and of species of experimental animal.

\section{SUMMARY}

Actions of veratramine on the central nervous system were studicd in various species of experimental animal and the following results were obtained.

1. Veratramine injected intravenously elicited excitation such as tremor, struggling movement and sometimes rotation in all species of animal tested, namely in rabbits, guinea pigs, cats and dogs. When injected intracisternally in rabbits, the similar excitation was induced. Intracisternal effective doses for veratramine struggling and for tremor were about $1 / 15$ and $1 / 20$ of intravenous doses respectively.

2. Ether, mephenesin and aminopyrine antagonized against veratraminc excitation in rabbits. Phenobarbital, diphenylhydantoin, trimethadione and morphine inhibited also the excitation but they were less active. Diphenhydramine, procaine and chlorpromazine had almost no effect.

3. The struggling caused by the intravenous veratramine in the cat of which cortical motor area or total cortex were removed, diminished its severity and irrcgularity. After ablation of bilateral hemisphere involving striatc body, the struggling turned to a rather regular running movement. The veratramine excitation was completely abolished by transection of brain between midbrain and pons. These data suggest that midbrain is responsible to initiate the veratramine cxcitation and other parts of brain rostral than midbrain participate in the accomplishment of struggling.

4. In EEG of rabbits, intravaenous veratramine evoked fast activities accompanied by spikes. In the mesencephalic preparation, veratramine did not elicit spikes.

5. Intracisternal veratramine in rabbits caused a rise of arterial pressure accompanicd 
by a respiratory inhibition. The hypertensive action was not modified by the transection of brain at the postcollicular level, suggesting that the medullary vasomotor center is stimulated by veratramine.

Acknowledgement. The author wishes to express the deepest gratitude to Prof. K. Tanaka for his continuous guidance and valuable advices.

\section{REFERENCLS}

1) SAlTo, K.: Bull. Chem. Soc. Japan 15, 22 (1940)

2) JACOBS, W.A. AND CRAiG, L.C.: J. biol. Chem. 160, 555 (1945)

3) KRAYER, O.: J. Pharmacol. 96, 422 (1949)

4) Kosterlitz, H.W., Krayer, O. AND Matallana, A.: Ibid. 113, 460 (1955)

5) KRAYER, O. AND VAN MAANEN, E.F.: I Iid. 97, 301 (1949)

6) KRAYER, O.: Ibid. 98, 427 (1950)

7) KRAYer, O., MANDOKI, J.J. AND MENDEZ, C.: I Iid. 103, 412 (1951)

8) KRAYer, O.: J. Mt. Sinai Hosp. 19, 53 (1952)

9) Krayer, O. AND OURisson, P.: J. Pharmacol. 112, 341 (1954)

10) KRAYeR, O., ARORA, R.B. AND MEILMan, E.: I idi. 113, 446 (1955)

11) MARSh, D.F., Herring, D.A. ANi Howard, A.: Ibid. 1C3, 172 (1951)

12) McCubbin, J.W. AND PACE, I.H.: Amer. J. Physiol. 167, 714 (1951)

13) Swiss, E.D. AND MAISON, G.L.: J. Pharmacol. 105, 87 (1952)

14) TANAKA, K.: Ibid. 113, 87 (1955)

15) HAYASHI, T.: Physiology of Brain (1944) (Japanese)

16) MAGoUn, H.W.: Physiol. Rev. 3?, 459 (1950)

17) FUNDERBURK, W.H. AND KING, E.E.: J. Pharmacol. 103, 343 (1951)

18) Kimura, N.: J. Yonago Med. Assoc. 5, 95 (1954) (Japanese)

19) Mishima, O.: Ibid. 5, 53 (1954) (Japanese)

20) Tanaka, K. aNd Mishima, O.: This Journal 3, 6 (1953)

21) Richter, H. AND ThOMA, H.: Arch. exp. Paih. Pharmak. 193, 622 (1939)

22) Cicardo, V.H.: Arch. int. Pharmacodyn. 94, 65 (1953)

23) KANNO, T.: Unpublished observation in this laboratory

24) WaNG, S.C., NCAI, S.H. A.ND GRossmaN, R.G.: J. Pharmacol. 113, 100 (1955) 